\title{
Evolving anti-disease strategies from biochemical pathogenesis of african trypanosomiasis
}

\begin{abstract}
African trypanosomes are transmitted biologically by tsetse flies (Glossina spp) to humans and animals to cause African trypanosomiasis or trypanosomosis (sleeping sickness or Ngana). The pathology associated with the disease includes blood dyscrasia (anemia, leucopenia, thrombocytopenia), organ damage and inflammation. The infected host's metabolism is altered in response to the disease. The biochemical configuration and functions of the cell membrane, mitochondria, and cytosolic components are deranged by the infection. Cells of the infected host respond biochemically by producing chemical signals which regulate biochemical pathways, influence inflammatory responses and modify structural components. Several biochemical tools have been used to elucidate the biomolecules expressed in the disease. These biomolecules are also markers for diagnostic purposes and pathophysiological evaluations. The technologies involved in the biochemical studies are expanding from basic techniques of colorimetry, spectophotometry, and chromatography to sophisticated mass spectrometry. There are new trends employing systematics such as genomics, proteomics and metabolomics (metabonomics). The goal is to identify molecules and biochemical loci which can provide avenue for anti-disease strategies needed to treat and control the disease.
\end{abstract}

Volume 3 Issue 2 - 2018

\author{
Igbokwe 10 \\ Department of Veterinary Pathology, University of Maiduguri, \\ Nigeria
}

Correspondence: Igbokwe IO, Department of Veterinary Pathology, University of Maiduguri, PMB 1069, Maiduguri, Nigeria, Email ikeigbokwe@gmail.com

Received: April 24, 2017 | Published: March 07, 2018

\section{Introduction}

African trypanosomiasis is an important protozoan disease of humans and animals in many sub-saharan African countries where the disease is transmitted biologically by tsetseflies (Glossina $s p p$ ) or mechanically by biting flies (Tabanids and Stomoxys). The pathogenic trypanosomes have specific hosts (Figure 1). The diseases caused by the trypanosomes are characterized by anemia, leucopenia, thrombocytopenia, inflammation of organs, tissue degeneration, apoptosis and necrosis. ${ }^{1,2}$ Cellular pathology caused by the disease is explored through researches using tools in biochemistry and molecular biology which examine biofluids, biomembranes, cytosolic compositions and capture molecular fingerprints associated with the disease processes. The review is aimed at briefly highlighting some of the biochemical elucidations of the pathogenesis of African

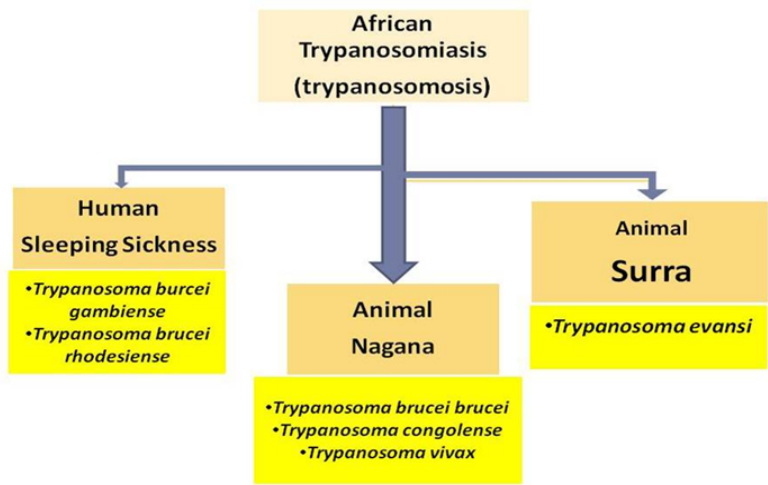

trypanosomiasis from which anti-disease strategies would evolve.

Figure I Types of African trypanosomiasis, their common names and the trypanosome species involved.

\section{Genomics in trypanosomiasis research}

Molecular biologists have sequenced the trypanosome genome..$^{3-6}$
The entire genome contains about 10,000 genes and $10 \%$ of them are variable surface glycoprotein (VSG) genes. The VSG genes provide a molecular basis for antigenic variation in trypanosomes during infections. Only one VSG gene is expressed at any particular time while others are transcriptionally silent. Antigenic variation enables the parasite to evade the host's immune defence and inundate the host with a heavy antigenemia as the surface coat is discarded regularly. The dynamics of VSG gene expression is expected to expose the conserved portions of the VSG proteome that is yet to be fully understood, and knowledge of it may be the basis for vaccine development against trypanosomes. ${ }^{7}$ Furthermore, trypanosome genomics may be a useful means of refining parasite identification, comparing species and life cycle stages, targeting gene locations for new drug development and improving understanding of drug intervention and resistance development. Recently, the pathogenicity of trypanosomes was linked to multiple genes, which implied that the differences in disease processes caused by various trypanosome species might have genetically-based incitement from the parasites. ${ }^{8}$ Variation in susceptibility of infected hosts to the pathogenic effects of trypanosomes has a connection with the host's genetic resources. Genetic resistance to African trypanosomiasis is termed trypanotolerance and it occurs in some breeds of livestock, species of wildlife, strains of laboratory animals and humans. ${ }^{9,10}$ Trypanotolerance is an inheritable trait with genetic parameters of indicators such as control of parasitaemia and limiting of pathological effects. ${ }^{11,12}$ In cattle breeds, trypanotolerance arises from improved parasite control and haemtopoietic tissue genotype which improves control over development of anaemia..$^{13,14}$ The capacity to limit anaemia development is more important for survival and productivity in cattle than parasite control. ${ }^{15}$ Therefore, understanding the genetic and transcriptional factors involved in trypanotolerance is relevant to the control of the disease ${ }^{9}$ and advances in host genetics in relation to infection are expected to help in the evolution of anti-disease strategies. ${ }^{12}$ Whole transcriptome analysis has revealed the gene variations related to the trypanotolerance trait in cattle. ${ }^{16}$ Trypanotolerance was associated with increases, at the early phase, in transcripts for genes encoding proinflammatory cytokine mediators during infection of N'Dama cattle. ${ }^{17}$ Temporal 
peripheral blood mononuclear cell gene expression in response to trypanosome infection was also recognised to be contributory to trypanotolerance in N'Dama cattle. ${ }^{18}$ There were differential gene expressions between trypanotolerant and trypanosusceptible breeds which underscored the genetic basis of the susceptibility traits. ${ }^{18}$ Serial analysis of gene expression (SAGE) from peripheral blood mononuclear cells led to the emergence of bioinformatic identification of upregulated and downregulated genes involved in trypanotolerance in cattle. ${ }^{19}$ Tumour necrosis factor gene was reported to play a role in resistance to trypanosome infection in mice. ${ }^{20}$ Higher serum amyloid A expression levels may support trypanotolerance in cattle..$^{21}$ Host genetic deficiencies of complement lectin pathway factors contribute to infection susceptibility and disease progression. ${ }^{22}$

The genetic approach to understand the identified mechanisms of natural resistance to trypanosomiasis ${ }^{23}$ is supposed to provide insights on strategies for breeding selections so that the animal production system can insure the purity of genes of trypanotolerant breeds in livestock populations, and hence control the scourge of animal trypanosomiasis in endemic regions. ${ }^{24}$ It is noteworthy that introgression of genes of trypanosusceptible breeds into West African dwarf goat populations is occurring leading to loss of their trypanotolerance. ${ }^{25}$ Therefore, there is need to explore the host genome for the genetic architecture of the trypanotolerance trait and identify candidate genes to be recognised as selection signatures. ${ }^{26}$ In line with this proposition, several attempts have been made to characterise the candidate genes for trypanotolerance in cattle and ascertain whether the genes are under positive selection. ${ }^{27-29}$ Further details on the genetic basis of trypanotolerance across various species are available in a recent review by Yaro et al., ${ }^{24}$ and the limitations of genetic studies with regard to their application in genomic selection are also reviewed by Meuwissen et al., ${ }^{30}$ offering insights into improved genomic selection in animal breeding.

\section{Biochemical interaction of trypanosomes with infected host}

Trypanosomes, in body fluids, consume the host's supplies (Figure 2) of carbohydrates, proteins, lipids and some micronutrients as their source of nutrients and release metabolites such as pyruvate, phenylpyruvate and tryptophol into the blood circulation as reviewed by Igbokwe. ${ }^{1}$ The trypanosome metabolites may cause metabolic acidosis and inhibit tricarboxylic acid cycle and glycogenesis in the infected hosts. ${ }^{1,31}$ The parasites (Figure 3) also produce proteases, neuraminadases, phospholipases, lipopolysaccharides and free fatty acids which contribute to the pathogenic mechanisms of the disease. ${ }^{1}$ Antigens are released from trypanosomes to stimulate the immune system of the host, which produce biomolecules such as immunoglobulins, lymphokines, nitric oxide and free radicals for defence against the infection. ${ }^{1}$ A trypanolytic factor in human serum, apoL-I, in high density lipoprotein is lethal for T. brucei. ${ }^{32}$ Trypanotoxic molecules (tumor necrosis factor, nitric oxide and interferon) produced by macrophages kill the parasites and antibodyopsonised trypanosomes are phagocytosed. ${ }^{33}$

\section{Biochemistry of erythrocyte abnormalities}

Erythrophagocytosis, after molecular alteration of erythrocyte membrane surface (Figure 4), in the macrophage phagocytic system (MPS) is the hallmark of trypanosomiasis. ${ }^{1}$ Trypanosome proteases and neuraminidases cleave surface sialic acids from surface membranes of erythrocytes and render them susceptible to phagocytosis. . $34,35^{2}$ Also, oxidative stress in trypanosome infections has implications on erythrocyte membrane stability and fluidity. Erythrocytes with altered membranes following peroxidative injuries would be phagocytosed or fragmented and lysed intravascularly. ${ }^{1,36-41}$ The transfer of VSG from trypanosomes to erythrocyte membranes and the anchorage of immunologically derived molecules on erythrocyte membranes have been shown to lead to erythrocyte clearance by MPS..$^{42}$ Perturbation of membrane function has been suggested by the report of decreased erythrocyte potassium and increased erythrocyte calcium ion contents in trypanosome infections in association with decreased osmotic resistance. ${ }^{43}$ It was presumed that the functions of NaK-ATPase and CaMg-ATPase may be affected in the infection, ${ }^{1}$ because these membrane-associated enzymes were reduced in activities during infection in the brain, kidney and testis. ${ }^{44-46}$ Mijares et al., ${ }^{47}$ confirmed in their report that erythrocyte Ca-ATPase activity decreased in Trypanosoma evansi infection. Trypanotolerance has been associated with higher erythrocyte levels of zinc and manganese, ${ }^{48}$ increased erythrocyte sialic acid content, ${ }^{49}$ differential erythrocyte sialic acid composition ${ }^{50}$ and erythrocyte surface sialic acid moieties characterised by more O-acetyl than glycolyl groups. ${ }^{51}$

Figure 2 Trypanosomes absorb and metabolize host's nutrients and release

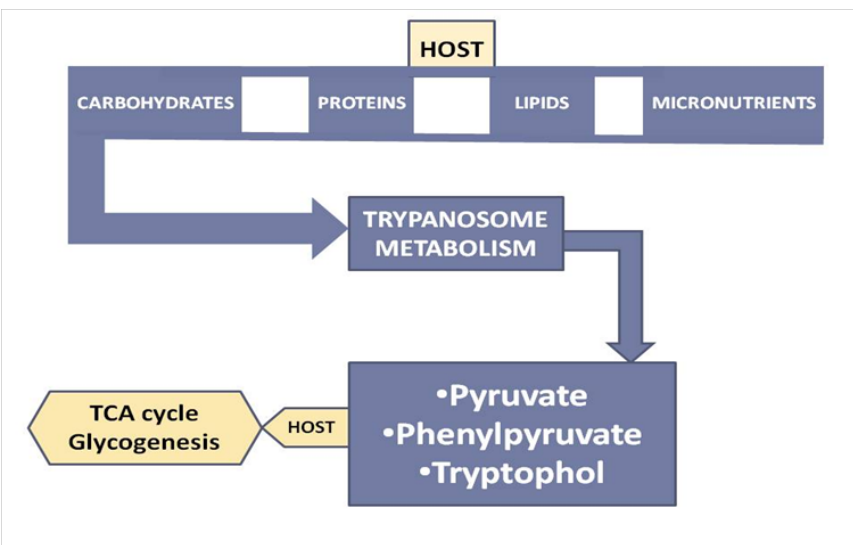

metabolites.

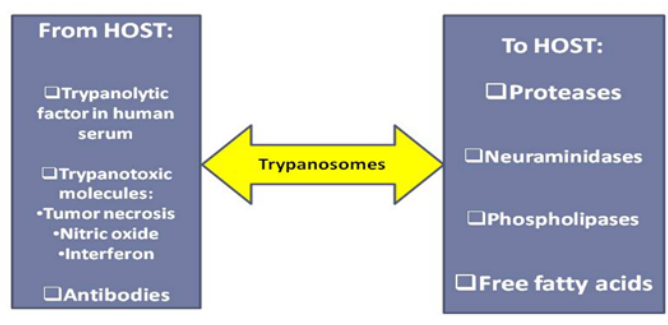

Figure 3 Biomolecules from the host attack trypanosomes and biomolecules from trypanosomes mediate disease in the host.

\section{Biochemistry of dyserythropoiesis}

The capacity of an infected host to resist anaemia, and respond to it through enhanced erythropoiesis, are valuable traits in trypanotolerance. More than two decades ago, there was indirect evidence that erythropoietin activity might be reduced in the plasma 
of trypanosome-infected animals. ${ }^{52}$ The finding was followed with a hypothesis that trypanosome neuraminidase could destroy the in vivo biologic activity of erythropoietin (EPO), a glycosylated protein, by cleaving the terminal sialic acid residues ${ }^{53}$ and this was subsequently supported by others..$^{34}$ Later, it was reported that EPO activity increased in infected calves that had high erythropoietic potential, but the EPO had impaired activity because of inhibitory factors in the plasma, thus supporting our earlier findings. ${ }^{54,55}$ Suliman et al. ${ }^{56}$ reported that the levels of EPO and receptors of EPO in infected Boran cattle were inadequate for the degree of anaemia during trypanosome infection. Downregulation of EPO receptor expression seems to impact the proliferation, differentiation, and maturation of the erythroid precursors and leads to inadequate erythropoiesis in the infected animals. ${ }^{57}$ The survival rates of infected mice were dramatically improved by treatment with recombinant human erythropoietin, ${ }^{57}$ which is relevant to the report that increased erythropoietic potential and ability to prevent anemia are related to trypanotolerance. ${ }^{15}$ Trypanotolerance was associated with higher levels of EPO receptor transcripts in the bone marrow. ${ }^{56}$ Strong immune response (Type-1) is mounted during the early stages of infection and it is associated with the classical hyperactivation of macrophages which are engaged in erythrophagocytosis. ${ }^{1,33}$ The engulfed erythrocytes release haemoglobin from which iron $\left(\mathrm{Fe}^{2+}\right)$ is extracted in the phagosome and moved into the cytosol in the ferrous state to be converted to ferritin $\left(\mathrm{Fe}^{3+}\right)$ for storage. Extracellular exportation of ferrous iron occurs on demand via ferroportin-1 (FPN-1). The extracellular $\mathrm{Fe}^{2+}$, upon conversion to ferric iron $\left(\mathrm{Fe}^{3+}\right)$ through ceruloplasmin (CP), is bound to transferrin (Tf) and transported, mainly to the bone marrow to be used in erythropoiesis. In trypanosome-infected mice, there were increases in gene expressions of FPN-1, Tf and CP only in the acute phase but not in the chronic phase, suggesting that export of iron was hampered in the chronic phase of infection with indication of iron sequestration, as evidenced by increased ferritin expression, enhanced uptake of erythrocytes and iron-containing compounds. ${ }^{58}$ Depletion of ascorbic acid pool of the host during the infection was postulated as a possible cause of the iron sequestration (Figure 5), since ascorbic acid is required to mobilize iron from the ferric state of the stored iron to the ferrous state for exportation to the extracellular compartment en route to the bone marrow ${ }^{31}$ and supplementation of the vitamin may eliminate the iron blockade and allow enhanced erythropoiesis after correction of any ascorbic acid deficit as already reported in trypanosomiasis. ${ }^{59}$ The depression of serum levels of some free amino acids occur in trypanosome infections and may be responsible for the reduction in the rate of synthesis of the globin moiety of haemoglobin as previously reviewed. ${ }^{31}$ Globin synthesis precedes heme synthesis and is nearly complete by the time haemoglobin synthesis begins. Thus, reduced availability of required amino acids for globin synthesis may also slow down erythropoiesis.

\section{Oxidative stress in trypanosome infections}

Oxidative stress is an imbalance between free radical generating and scavenging activities, resulting in the accumulation of oxidation products which are capable of causing tissue damage. A free radical is highly reactive and can be produced from metal or enzyme catalyzed redox reactions of cells. Because bloodstream forms lack catalase and GSH peroxidase activities, hydrogen peroxide accumulates in the trypanosome to a concentration of about $70 \mu \mathrm{M} .{ }^{60,61}$ Therefore, hydrogen peroxide and free radicals may be discharged into the extracellular fluid by the parasite in infected animals. Activated macrophages are capable of increasing their oxygen uptake after which they release large amounts of superoxide anions into the extracellular fluid. ${ }^{62}$ The generation of free radicals is mediated by pro-inflammatory cytokines such as tumour necrosis factor alpha (TNF-a), gamma interferon (IFN-g), interleukin 1 Beta (IL-1B) and IL- 6 produced by activated macrophages. ${ }^{33}$ Malondialdehyde (MDA) is the most abundant biomarker produced as a consequence of lipid peroxidation after free radical attack of cellular lipids. ${ }^{63}$ The accumulation of MDA in tissues or biological fluids is indicative of the extent of free radical generation, oxidative stress and tissue damage. ${ }^{64}$ Reports have shown that trypanosome infections increase MDA production in the host as an indication of oxidative damage. ${ }^{37,65}$

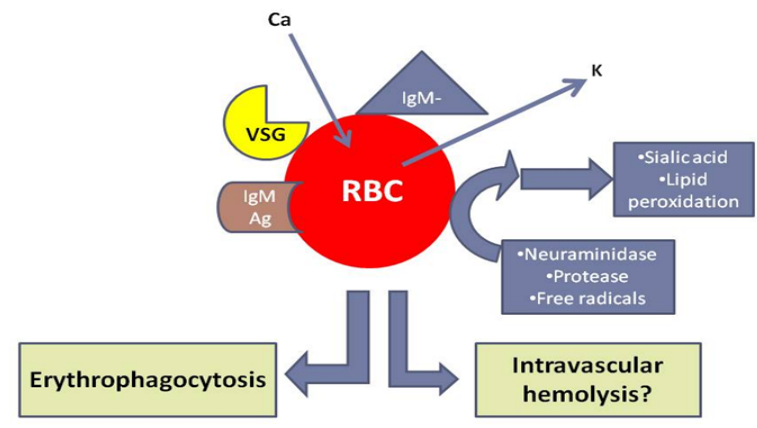

Figure 4 Alterations of the erythrocyte membrane in African trypanosomiasis.

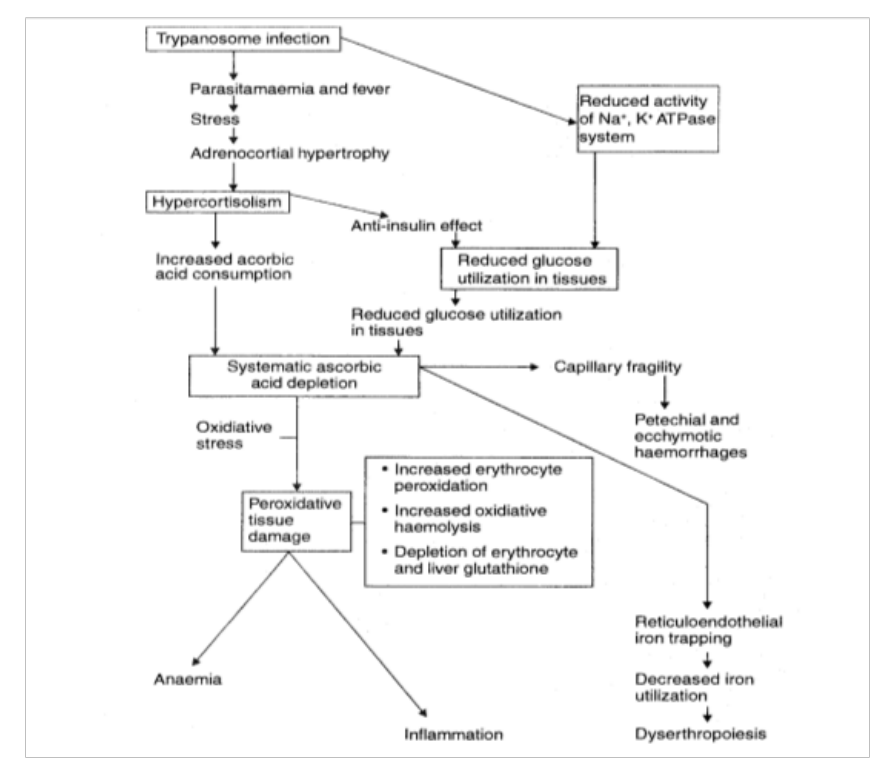

Figure 5 Ascorbic acid (Vitamin C) depletion and oxidative stress in the pathogenesis of trypanosomiasis. See earlier review by Igbokwe. ${ }^{31}$

Methemoglobin (MHb) is the oxidation product of haemoglobin which occurs when ferrous iron in hemoglobin is oxidized to the ferric state and may aggravate oxidative damage to erythrocytes. Increased $\mathrm{MHb}$ in $T$. evansi-infected camels provide further evidence of erythrocytic oxidation and free radical generation in the erythrocytes during infection. ${ }^{37}$ Nitric oxide was generated in excessive amounts in T. brucei, T. b. rhodesiense, T. evansi-infected individuals. ${ }^{37,66,67}$ Nitric oxide may react with superoxide anions to produce peroxynitrite anion (PNA), or by the Fenton reaction to produce hydroxyl radical. ${ }^{68}$ 
Both PNA and hydroxyl radicals are the most potent oxidizing agents which can initiate lipid peroxidation in the cell membranes causing cellular damage ${ }^{63}$ Furthermore, nitric oxide can cross the erythrocyte membrane and react with SH group resulting in nitrosyl-haemoglobin, which slowly oxidizes to $\mathrm{MHb}$ in the presence of oxygen. ${ }^{69}$ Direct correlation of nitric oxide production with the development of anaemia in T. brucei-infected mice was reported, and the treatment with nitric oxide blockers led to a significant reduction of the anaemia ${ }^{67}$ Positive correlations of enhanced nitric oxide production with erythrocyte MDA generation and $\mathrm{MHb}$ formation were reported as evidence of the involvement of nitric oxide production in erythrocytic oxidation during $T$. evansi infection while the negative correlation of nitric oxide, erythrocyte MDA and MHb formation to packed cell volume indicated that the enhanced oxidation of the erythrocytes contributed to the progression of the anaemia in chronic $T$. evansi-infected in camels. ${ }^{37}$ The antioxidant systems involved in the protection against free radicals are superoxide dismutase (SOD), GSH-peroxidase, catalase (CAT), glutathione (GSH), antioxidant vitamins A, E and C. When the antioxidant systems are challenged by free radical generating events during the disease process, the activities of the antioxidant enzymes are affected and the antioxidant molecules are depleted. The activity of erythrocyte GSH peroxidase was increased in trypanosome-infected mice, ${ }^{40}$ whereas erythrocyte SOD activity decreased in T. evansi-infected camels. ${ }^{37}$ Most importantly, antioxidant GSH and vitamins $\mathrm{A}$ and $\mathrm{C}$ are depleted in these infections. ${ }^{38,59,70}$ The assessment of the antioxidant deficit of erythrocytes in trypanosome infections was also done by in vitro peroxidation test where the cells were challenged with peroxide load and found to have increased susceptibility. ${ }^{36}$ Increased susceptibility of erythrocytes to oxidative hemolysis was also an indication of the decline in antioxidant capacity of erythrocytes during infection. ${ }^{71}$

\section{New approach to metabolic studies in infected hosts}

Cellular homeostasis depends on cell membrane integrity, respiration and energy generation. Any deviation means a tendency towards cellular degeneration, a reversible cellular state or cell death, a terminal state leading to cellular disintegration. Indications that trypanosome infections affect cell metabolism are being discovered and areas of science known as proteomics and metabonomics are deployed to improve our understanding. The central issues on metabolic dysfunctions during infections include the increases in catabolic processes, downregulation of energy generating pathways, depletion of energy molecules with depressed intracellular glucose delivery and loss of capacity to endogenously generate antioxidant capacity. ${ }^{31,72}$ With proteomic studies, the protein configurations of the altered state are studied with better efficiency and these protein expressions from the parasite and host cells provide opportunities in drug development. ${ }^{73}$ Also, metabolic profiling enables us track the systemic weakness that develop with the progression of the disease in order to present a global perspective to the pathophysiology of the disease and give insights into most metabolic dysfunctions. ${ }^{74}$

\section{Anti-disease strategies against trypanosomiasis}

Strategies conceived to reduce or eliminate the burden of the disease in the parasite-host interaction, would be expected to mitigate paradigmatic parasitism, where parasite population increases and the host loses fitness from organic lesions associated with systemic dysfunctions. In this context, anti-disease strategies against African trypanosomiasis, in the broadest sense, may include: a) prevention of infection by breaking trypanosome transmission through avoiding contact with vectors by using odour-baited traps and screens to remove vectors from the vicinity of the host,$^{75}$ deploying synthetic or natural animal-derived vector repellents on the host $\mathrm{t}^{76,77}$ and/or elimination of vectors in the environment by aerial insecticide sprays $^{78-81}$ and integrated vector control using sterile insect technique; ${ }^{82,83} \mathrm{~b}$ ) reduction of the virulence or attenuation of trypanosomes by genomic or transcriptional manipulation during propagation in the vector or host $;{ }^{84,85} \mathrm{c}$ ) development of a vaccine and vaccination to prevent disease through protective immunity ${ }^{86} \mathrm{~d}$ ) enhancing natural innate resistance or immunity ${ }^{17,20,87-89}$ that controls parasitaemia by genomic selection of the host population; ${ }^{26,30} \mathrm{e}$ ) reduction of host immunopathological responses responsible for pathophysiologic conditions associated with the disease; ${ }^{33,90} \mathrm{f}$ ) interventions to ameliorate or abet somatic dysregulations and dysfunctions; $;{ }^{91-94} \mathrm{~g}$ ) clearance of parasitaemia by effective chemotherapy. ${ }^{95,96}$ Antoine-Moussiaux et al., ${ }^{97}$ considered, in a review, that anti-disease strategies could be targeted at treatments which did not eliminate the trypanosomes, but prevented the invasion of the brain by maintenance of blood brain barrier, neutralized the toxic products of trypanosomes, modulated the immune processes towards regulation of inflammation, reduction of effect of tumour necrosis factor, amplification of TGF-beta 1 and prevention of apoptosis of lymphocytes. Therefore, the anti-disease strategies propose to promote disease tolerance which is an ability of the host to limit the health consequences of the infective pathogen in spite of burden of infection. ${ }^{98,99}$

\section{Concluding perspectives}

The strategies directed against disease-producing pathophysiological processes to engender trypanotolerance or resistance to the disease require continuous attention in research, because several published results as reviewed here, so far, have provided insights as to the themes for re-evaluation and re-emphasis. It is imperative to keep this direction of research because of the failure of control measures. Complete elimination of vectors has not been feasible in most endemic environments and multi-drug resistance has made chemotherapy less effective, causing relapse of patent infections in treated cases. Sometimes, diagnostic techniques may not be able to detect very low parasitemia and latent infections when the parasites are sequestered in the extravascular compartments. Trypanosomes in infected hosts migrate to privileged extravascular sites which may be adipose tissues, dermis and subcutis of the skin, where they localize and serve as sources for subsequent recrudescence of active patent infection. ${ }^{100-102}$ Therapeutic agents need to be capable of reaching tissues with sequestered parasites which are shielded from drug effects and in the event of failure to do so, the infected hosts has to recruit endogenous anti-disease strategies to control the infection or be supported exogenously with anti-disease interventions. Even in untreated cases, an argument is tenable for strategies investing in disease mitigation of the infected hosts. A valid approach is to evolve the anti-disease strategies from the understanding of the biochemical abnormalities produced in the development of the disease so that interventions could support the host in averting or remedying the biochemical lesions.

\section{Acknowledgements}

None.

\section{Conflict of interest}

None. 


\section{References}

1. Igbokwe IO. Mechanisms of cellular injury in African trypanosomiasis. Veterinary Bulletin. 1994;64(7):611-620.

2. Happi AN, Milner Jr DA, Antia RE. Blood and tissue leukocyte apoptosis in Trypanosoma brucei infected rats. Journal of Neuroparasitology. 2012;3:10.

3. Berriman M, Ghedin E, Hertz-Fowler C, et al. The genome of the African trypanosome Trypanosoma brucei. Science. 2005;309(5733):416-22.

4. Jackson AP, Sanders M, Berry A, et al. The genome sequence of Trypanosoma brucei gambiense, causative agent of chronic human African trypanosomiasis. PLoS Negl Trop Dis. 2010;4(4):e658.

5. Jackson AP, Berry A, Aslett M, et al. Antigenic diversity is generated by distinct evolutionary mechanisms in African trypanosome species. Proc Natl Acad Sci U S A. 2012;109(9):3416-21.

6. Gibson W. The origins of the trypanosome genome strains Trypanosoma brucei brucei TREU 927, T. b. gambiense DAL 972 T. vivax Y486 and T. congolense IL3000. Parasit Vectors. 2012;5:71.

7. Nok AJ (2009) African trypanosome. Vaccines for Biodefense and Emerging and Neglected Diseases. Elsevier Inc.

8. Sistrom M, Evans B, Bjornson R, et al. Comparative genomics reveals multiple genetic backgrounds of human pathogenicity in Trypanosoma brucei complex. Genome Biology Evolution. 2014;6(10):2811-2819.

9. Murray M, Trail JC, Davis CE, et al. Genetic resistance to African trypanosomiasis. J Infect Dis. 1984;149(3):311-319.

10. Berthier D, Breniere SF, Bras-Goncalves R, et al. Tolerance to trypanosomatids: A threat or a key for disease elimination? Trends in Parasitology. 2016;32(2):157-168.

11. D Ieteren GD, Authie E, Wissocq N, et al. Trypanotolerance, an option for sustainable livestock production in areas at risk from trypanosomiasis. Rev Sci Tech. 1998;17(1):154-175.

12. Courtin D, Berthier D, Thevenon S, et al. Host genetics in African trypanosomiasis. Infect Genet Evol. 2008;8(3):229-238.

13. Roelants GE. Natural resistance to African trypanosomiasis. Parasite Immnol. 1986;8(1):1-10.

14. Naessens J, Leak SG, Kennedy DJ, et al. Responses of Bovine chimaeras combining trypanosomosis resistant and susceptible genotypes to experimental infection with Trypanosoma congolense. Vet Parasitol. 2003;111(2-3):125-142.

15. Naessens J. Bovine trypanotolerance: A natural ability to prevent anaemia and haemaphagocytic syndrome? International Journal of Parasitology. 2006;36(5):521-528

16. Berthier D, Chantal I, Thevenon S, et al. Study of bovine trypanotolerance by whole transcriptome analysis. Ann NY Acad Sci. 2008;1149:71-76.

17. O Gorman GM, Park SD, Hill EW, et al. Cytokine mRNA profiling of peripheral blood mononuclear cells from trypanotolerant and trypanosusceptible cattle infected with Trypanosoma congolense. Physiological Genomics. 2006;28(1):53-61.

18. O Gorman GM, Park SD, Hill EW, et al. Transcriptional profiling of cattle infected with Trypanosoma congolense highlights gene expression signatures underlying trypanotolerance and trypanosusceptibility. $B M C$ Genomics. 2009;10:207.

19. Berthier D, Quere R, Thevenon S, et al. Serial analysis of gene expression (SAGE) in bovine trypanotolerance: preliminary results. Genet Sel Evol. 2003;35(Suppl 1):S35-S47.

20. Iraqi F, Sekikawak K, Rowlands J, et al. Susceptibility of tumour necrosis factor-alpha genetically deficient mice to Trypanosoma congolense infection. Vet Immunol Immunopathol. 2001;23:445-451.

21. Meade KG, O Gorman GM, Hill EW, et al. Divergent antimicrobia peptide (AMP) and acute phase protein (APP) responses to Trypanosoma congolense infection in trypanotolerant and trypanosusceptible cattle. Mol Immunol. 2009;47(2-3):196-204.

22. Cestari I, Evans-Osses I, Schlapbach LJ, et al. Mechanisms of complement lectin pathway activation and resistance by trypanosomatid parasites. Mol Immunol. 2013;53(4):328-334.

23. Naessens J, Teale AJ, Sileghem M. Identification of mechanisms of natural resistance to African trypanosomiasis in cattle. Vet Immunol Immunopathol. 2002;87(3-4):187-194.

24. Yaro M, Munyard KA, Stear MJ, et al. Combatting African animal trypanosomiasis (AAT) in livestock: The potential role of trypanotolerance. Vet Parasitol. 2016;225:43-52.

25. Geert S, Osaer S, Goossens B, et al. Trypanotolerance in small ruminants of sub-Saharan Africa. Trends in Parasitology. 2009;25(3):132-138.

26. Dayo GK, Thevenon S, Berthier D, et al. Detection of selection signatures within candidate regions underlying trypanotolerance in outbred cattle populations. Mol Ecol. 2009;18(8):1801-1813.

27. Alvarez I, Perez-Pardal L, Traore A, et al. Lack of haplotype structuring for two candidate genes for trypanotolerance in cattle. J Anim Breed Genet. 2016;133(2):105-114

28. Alvarez I, Perez-Pardal L, Traore A, et al. Lack of specific alleles for bovine chemokine (C-X-C) receptor type 4 (CXCR4) gene in West African cattle questions its role as a candidate for trypanotolerance. Infect Genet. 2016;42:30-3.

29. Alvarez I, Perez-Pardal L, Traore A, et al. African cattle do not carry unique mutation on the exon 9 of the ARHGAP19 gene. Anim Biotechnol. 2016;27(1):9-12

30. Meuwissen T, Hayes B, Goddard M. Genomic selection: a paradigm shift in animal breeding. Animal Frontiers. 2016;6(11):6-14.

31. Igbokwe IO. Nutrition in the pathogenesis of African trypanosomiasis Protozoological Abstracts. 1995;19(12):797-807.

32. Vanhamme L, Pays E. The trypanosome lytic factor of human serum and the molecular basis of sleeping sickness. Int J Parasitol 2004;34(8):887898.

33. Vincendeau P, Bouteille B. Immunology and immunopathology of African trypanosomiasis. Annals of the Brazilian Academy of Sciences. 2006;78(4):645-665.

34. Adamu S, Ibrahim NDG, Nok AJ, et al. Sialyltransferase activity probably counteracts that of sialidase as one of the possible mechanisms of natural recovery or stabilization of erythrocyte mass in trypanosomeinfected animals - A perspective. Afri J of Biotechnol 2008;7:4992-5001.

35. Guegan F, Plazolles N, Baltz T, et al. Erythrophagocytosis of desialylated red blood cells is responsible for anaemia during Trypanosoma vivax infection. Cellular Microbiology. 2013;15(8):1285-1303.

36. Igbokwe IO, Esievo KAN, Saror DI, et al. Increased susceptibility of erythrocytes to in vitro peroxidation in acute Trypanosoma brucei infection of mice. Vet Parasitol. 1994;55(4):279-286.

37. Saleh MA, Al-Salahy MB, Sanousi SA. Oxidative stress in blood of camels (Camelus dromedaries) naturally infected with Trypanosoma evansi. Vet Pathol. 2009;162(2-4):192-9.

38. Igbokwe IO, Lafon JY, Umar IA, et al. Erythrocyte and hepatic glutathione concentrations in acute Trypanosoma brucei infection of rats. Tropical Veterinarian. 1998;16:81-83. 
39. Wolkmer P, da Silva AS, Traesel CK, et al. Lipid peroxidation associated with anemia in rats experimentally infected with Trypanosom evansi. Vet Parasitol 2009; 165:41-46

40. Omer OH, Mousa HM, Al-Wabel N. Study on the antioxidant status of rats experimentally infected with Trypanosoma evansi. Vet Parasitol. 2007; $154: 142-145$.

41. RanjithKumar M, Kamili NM, Saxena A, et al. Disturbance of oxidant/ antioxidant equilibrium in horses naturally infected with Trypanosoma evansi. Vet Parasitol. 2011;180: 349-353.

42. Rifkin M R, Landsberger FR. Trypanosome variant surface glycoprotein transfer to target membranes: A model for the pathogenesis of trypanosomiasis. Proc Nati Acad Sci USA. 1990;87:801-805.

43. Ogunsanmi AO, Taiwo VO. Comparative studies on erythrocyte calcium, potassium, haemoglobin concentration, osmotic resistance and sedimentation rates in grey duiker (Sylvicapra grimmia), sheep and goats experimentally infected with Trypanosoma congolense. Vet Arhive. 2004;74(3):201-216

44. Nok AJ, Esievo KAN, Ajibike MO, et al. Modulation of the calcium pump of the kidney and testis of rats infected with Trypanosoma congolense. $J$ Comp Pathol. 1992;107(1):119-123.

45. Nok AJ, Esievo KAN, Ukoha AI, et al. Kidney NaK-ATPase: Kinetic study of rats during chronic infection with Trypanosoma congolense. $J$ Clin Biochem Nutr 1992;13:73-79.

46. Nok AJ, Esievo KAN, Ukoha AI, et al. Brain NaK-ATPase and cholesterol in acute experimental trypanosomiasis. Cell Biochem Funct 1992;10:233-236.

47. Mijares A, Vivas J, Abad C, et al. Trypanosoma evansi: effect of experimental infection on the osmotic fragility, lipid peroxidation and Calcium-ATPase activity of rat red blood cells. Expermental Parasitology. 2010;124(3):301-5.

48. Owolaja OA, Antia RE, Ojejide A. Trace element levels in plasma/serum and erythrocytes of keteku and white fulani cattle. Trop Anim Hlth Prod. 1997;29:2-6.

49. Esievo KA, Saror DI, Kolo MN. Erythrocyte surface sialic acid in Ndama and Zebu cattle. Journal of Comparative Pathology. 1986;96(1):95-9.

50. Esievo KA, Jaye A, Andrews JN, et al. Electrophoresis of bovine erythrocyte sialic acids: existence of additional band in trypanotolerant Ndama cattle. Journal of Comparative Pathology. 1990;102(4):357-61.

51. Shugaba A, Umar I, Omage J, et al. Biochemical differences $(\mathrm{O}-$-acetyl and glycolyl groups) in erythrocyte surface sialic acids of trypanotolerant N'dama and trypanosusceptible Zebu cattle. Journal of Comparative Pathology. 1994;110(1):91-5.

52. Igbokwe IO, Anosa VO. Response to anaemia in experimental Trypanosoma vivax infection of sheep. Journal of Comparative Pathology. 1989;100:111-118.

53. Igbokwe IO. Dyserythropoiesis in animal trypanosomosis. Revue Elev Med vet Pays trop. 1989;42(3):423-429.

54. Andrianarivo AG, Muiya P, Logan-Henfrey LL. Trypanosoma congolense: high erythropoietic potential in infected yearling cattle during the acute phase of the anemia. Experimental Parasitology. 1996;82(2):104-111.

55. Buza JJ, Logan-Henfrey L, Andrianarivo AG, et al. Rise in erythropoietin concentrations in experimental Trypanosoma congolense infection of calves. Journal of Comparative Pathology. 1995;13(4):343-56.

56. Suliman HB, Longan-Henfrey L, Majiwa PA, et al. Analysis of erythropoietin and erythropoietin receptor genes expression in cattle during acute infection with Trypanosoma congolense. Exp Hematol. 1999;27(1):37-45.
57. Suzuki T, Ueta YY, Inoue N, et al. Beneficial effect of erythropoietin administration on murine infection with Trypanosoma congolense. Am J Trop Med Hyg. 2006;74(6):1020-1025.

58. Stijlemans B, Vankrunkelsven A, Brys L, et al. Role of iron homeostasis in trypanosomiasis-associated anemia. Immunobiology. 2008;213:823835 .

59. Mohammed HE, Beynen A. Ascorbic acid content of blood plasma, erythrocytes, leukocytes and liver in camels (Camelus dromedaries) with and without parasite infection. Journal for Vitamin and Nutrition Research. 2003;72(6):369-71.

60. Meshnick SR, Change KP, Cerami A. Hemelysis of the bloodstream forms of Trypanosoma brucei. Biochemical Pharmacology. 1977;26(20):19231928.

61. Baltz T, Baltz D, Giroud C, et al. Cultivation in a semi-defined medium of animal infective forms of Trypanosoma brucei, T. equiperdum, T. rhodesiense, T. gambiense. EMBO Journal.1985;4:1273-1277.

62. Schwacha MG, Loegering DJ. Respiratory burst capacity of activated macrophages is resistant to depression by erythrocyte phagocytosis. Inflammation.1992;16:285-294.

63. Halliwell B, Chirico S. Lipid peroxidation: its mechanism, measurement, and significance. Am J Clin Nutr 1993;57(supp 1): 715S-725S.

64. Gutteridge JMC. Lipid peroxidation and antioxidants as biomarkers of tissue damage. Clin Chem. 1995;41:1819-1828.

65. Eze J, Anene B, Chukwu C. Determination of serum and organ malondialdehyde (MDA) concentration, a lipid peroxidation index, in Trypanosoma brucei-infected rats. Comp Clin Pathol. 2008;17(2):67-72.

66. Sternberg JM. Elevated serum nitrate in Trypanosoma bruce rhodesiense infections: evidence for inducible nitric oxide synthesis in trypanosomiasis. Trans R Soc Trop Med Hyg. 1996;90(4):395.

67. Mabbott N, Sternberg J. Bone marrow nitric oxide production and development of anemia in Trypanosoma brucei-infected mice. Infect Immun. 1995;63(4):1563-1566.

68. Radi R, Peluff G, Alvarez MN, et al. Unraveling peroxynitrite formation in biological systems. Free Rad Biol Med. 2001;30(5): 463-488.

69. Herold S, Rock G. Reactions of deoxy-, oxy-, and methaemoglobin with nitrogen monoxide. J Biol Chem. 2003;278(9):6623-6634.

70. Ihedioha JI, Anwa AP. Liver retinol and carotenoid concentration of rats experimentally infected with Trypanosoma brucei. Trop Vet. 2002;20(1):1-7.

71. Ameh DA. Depletion of reduced gluthathione and the susceptibility of erythrocytes to oxidative haemolysis in rats infected with Trypanosoma brucei gambeinse. IRCS Med Sci. 1984;12:130.

72. Igbokwe IO, Mohammed C, Shugaba A. Fasting hyperglycaemia and impaired oral glucose tolerance in acute Trypanosoma brucei infection of rats. J Comp Pathol. 1998;118(1):57-63.

73. Roy N, Nageshan RK, Pallavi R, et al. Proteomics of Trypanosoma evansi infection in rodents. PLoS One. 2010;5(3):e9796.

74. Wang Y, Utzinger J, Saric J, et al. Global metabolic responses of mice to Trypanosoma brucei brucei infection. Proc Natl Acad Sci U S A. 2008;105:6127-6132.

75. Brightwell R, Dransffield RD, Kyorku C. Development of a low cost tsetse trap and odour baits for Glossina pallidipes and $G$. longipennis in Kenya. Med Vet Entomol. 1991;5(2):153-164.

76. Saini RK, Hassanali A. A 4-alkyl-substituted analogue of guaiaco shows greater repellency to savannah tsetse (Glossina spp). J Chem Ecol. 2007;33(5):985-995. 
77. Masiga DK, Igweta L, Saini R, et al. Building endogenous capacity for the management of neglected tropical diseases in Africa: The pioneering role of ICIPE. PLoS Negl Trop Dis. 2014;8(5):e2687.

78. Davies H. Further eradication of tsetse in the Chad and Gongola River Systems in North-Eastern Nigeria. Journal of Applied Ecology. 1971;8(2):563-578.

79. Park PO, Gledhill JA, Alsop N, et al. A large-scale scheme for the eradication of Glossina morsitans morsitans Westw. In Western Province of Zambia by aerial ultra-low-volume application of endosulfan. Bulletin of Entomological Research. 1972;61(3):373-384.

80. Spielberger U, Na Isa BK, Abdrrahim U. Tsetse (Diptera: Glossinidae) eradication by aerial (helicopter) spraying of persistent insecticides in Nigeria. Bulletin of Entomological Research. 1977;67(4):589-598.

81. Jordan AM. Principles of the eradication or control of tsetse flies. Nature 1978;273(5664):607-609.

82. Vreysen MJ, Saleh K, Mramba F, et al. Sterile insects to enhance agricultural development: the case of sustainable tsetse eradication on Unguja Island, Zanzibar, using area-wide integrated pest management approach. PLoS Negl Trop Dis. 2014;8(5):e2857

83. Abd-Alla AM, Bergoin M, Parker AG, et al. Improving Sterile Insect Technique (SIT) for tsetse flies through research on their symbionts and pathogens. Journal of Invertebrate Pathology. 2013;112(Supp 1):S2-10.

84. Namangala B, De Baetselier P, Brijs L, et al. Attenuation of Trypanosoma brucei is associated with reduced immunosuppression and concomitan production of Th2 lymphokines. J Infect Dis. 2000;181(3):1110-20.

85. Langousis G, Shimogawa MM, Saada EA, et al. Loss of the BBSome perturbs endocytic trafficking and disrupts virulence of Trypanosoma brucei. Proc Natl Acad Sci U S A. 2016;113(3):632-7.

86. Greca FL, Magez S. Vaccination against trypanosomiasis. Can it be done or is the trypanosome truly the ultimate immune destroyer and escape artist? Hum Vaccin. 2011;7(11):1225-33

87. Tabel H, Kaushik RS, Uzonna JE. Susceptibility and resistance to Trypanosoma congolense infections. Microbes Infect. 2000;2(13):1619 29.

88. Kaushik RS, Uzonna JR, Zhang Y, et al. Innate resistance to experimental African trypanosomiasis: differences in cytokine (TNK-alpha, IL-6, IL10 and IL-12) production by bone marrow derived macrophages from resistant and susceptible mice. Cytokine. 2000;12(7):1024-34.

89. Namangala B. Contribution of innate immune responses towards resistance to African trypanosome infections. Scand J Immunol. 2012; 75(1):5-15.
90. Stijlemans B, BaralTN, Guilliams M, etal.Aglycosylphosphatidylinositolbased treatment alleviates trypanosomiasis-associated immunopathology. J Immunol. 2007;179(6):4003-14.

91. Umar IA, Wuro-Chekke AU, Gidado A, et al. Effects of combined parenteral vitamin $\mathrm{C}$ and $\mathrm{E}$ administration on the severity of anaemia hepatic and renal damage in Trypanosoma brucei brucei infected rabbits. Vet Parasitol. 1999;85(1):43-7.

92. Umar IA, Toma I, Akombum CA, et al. The role of intraperitoneally administered $\mathrm{C}$ during Trypanosoma congolense infection of rabbits. African Journal of Biotechnology. 2010;9(32):5224-5228.

93. Ibrahim MA, Bindawa IM, Abdullahi SA. Antioxidant therapy against trypanosome infections: a review update. Curr Top Med Chem. 2016;16(20):2233-44.

94. Anschau V, Floriani MA, Tizatto MV, et al. Fish oil protects rat erythrocytes against oxidative stress caused by Trypanosoma evansi infection. Comparative Clinical Pathology. 2017;26(3):625-630.

95. Babokov P, Sanyaolu AO, Oyibo WA, et al. A current analysis of chemotherapy strategies for treatment of human African trypanosomiasis. Pathog Glob Health. 2013;107(5):242-52.

96. Giordani F, Morrison LJ, Rowan TG, et al. The animal trypanosomiasis and their chemotherapy: a review. Parasitology 2016;143(14):18621889.

97. Antoine-Mousiaux N, Buscher P, Desmecht D. Host-parasite interactions in trypanosomiasis: on the way to an antidisease strategy. Infect Immun. 2009;77(4):1276-84

98. Read AF, Graham AL, Raberg L. Animal defences against infectious agents: Is damage control more important than pathogen control. PLoS Biol. 2008;6(12):e4.

99. Medzitov R, Schneider DS, Soares MP. Disease tolerance as a defense strategy. Science. 2012;335(6071):936-941.

100. Mamman M, Moloo SK, Peregrine AS. Relapse of Trypanosoma congolense infection in goats after diminazene aceturate is not a result of invasion of the central nervous system. Annals of Tropical medicine and Parasitology. 1994;88(1):87-88.

101. Trindade S, Rijo-Ferreira F, Carvalho T, et al. Trypanosoma brucei parasites occupy and functionally adapt to the adipose tissue in mice. Cell Host Microbe. 2016;19(6):837-48.

102. Capewell P, Cren-traille C, Marchesi F, et al. The skin is a significant but overlooked anatomical reservoir for vector-borne African trypanosomes. ELife. 2016;5:e17716. 